\title{
Predictors of Sustainable Energy Technology Adoption Behavior in South-Western Nigeria
}

\author{
Ogunode, Philips Olatunde Adeola A. Ayodele \\ Department of Marketing, The Federal Polytechnic, Ado Ekiti, Nigeria
}

\begin{abstract}
This study focuses on the predictors of sustainable energy technology (SET) adoption behavior in south-western Nigeria. Although the extant literature is gorged with plethora of studies on sustainable energy technology adoption, studies that were conducted in a typical emerging economy like Nigeria in general and south-west Nigeria in particular are grossly under-researched and under-reported. The main objective of this study is to empirically investigate the predicting factors that influence the adoption of sustainable energy technology in south-western Nigeria. Based on the foregoing, the study adopted quantitative design and quota sampling as the research design and sampling method respectively. Questionnaire was the research instrument. The validity and the reliability of the research instrument were tested using construct validity and composite validity respectively. Hypothesized relationships were tested using structural equation modeling. It was found that performance expectancy, perceived value and effort expectancy have significant effect on the intention to adopt sustainable energy technology, while social influence, facilitating condition and intrinsic motivation do not. Also, it was revealed that there is a positive and significant relationship between intention to adopt sustainable energy technology and the actual adoption of sustainable energy technology. It was concluded that the study provided empirical support that Unified theory of acceptance and use of technology (UTAUT) provides a robust and comprehensive theoretical framework to predict, explain and describe sustainable energy technology adoption behaviour in a typical developing country context like Nigeria. The marketers of SET products should use price as their unique selling proposition to attract customers. Also, the quality of the SET products should conform with the expected performance of the product. Also, the SET marketers should endeavour that expected efforts of the prospective SET products consumers are met adequately since social influence, facilitating conditions and intrinsic motivation did not have significant effect on adoption intentions for SET.
\end{abstract}

Keywords: Sustainable energy technology, Adoption behavior, Intention to adopt, Unified theory of acceptance and use technology, Structural equation modeling, Nigeria.

DOI: $10.7176 / \mathrm{JESD} / 11-8-07$

Publication date: April $30^{\text {th }} 2020$

\section{Introduction}

The United Nations' World Commission on Environment and Development at Brundtland, Norway in 1987 provided an influential report that recognized the interdependences between the natural environment, human social welfare and economic activity, and the urgency to establish and maintain a dynamic balance between these three elements (Belz \& Peattie, 2014). Also, at Rio de Janeiro in 1992, it was established by the framework convention on climate change the need and urgency to protect, preserve and conserve our planet since we have no other planet where we can leave; there conventions served as an eye opener to the issue of sustainable living among the countries of the world (Hujits, Molin \& Stegs, 2012).

The rapid population growth, technological changes and unprecedented economic growth of the 20th century all combined to pose a number of challenges for the new century $(21 \mathrm{st})$. These factors are as a result of the consumption of natural resources through human activities to satisfy his wants and needs without any consideration for the social and natural environmental degradation such as ozone layer depletion, global warming, acid rain and sooth effect among others. In the developing country like Nigeria that has abundance of alternative source of energy that can help halt the menace of environmental degradation, is yet to harness these potentials to the fullest; (solar and wind energy in the north and south-west, abundant bio-mass energy in the south-south and south-east).

Targeting sustainable energy source is the major escape route from further degrading our dear planet. In this context, sustainable energy sources like solar, wind, and biomass which are abundant in Nigeria have great potential to contribute to the sustainable development goals achievement by providing a clean and green environment, large chunk of revenue generation and create numerous jobs (Rio \& Burgillo, 2007). Put pointedly, the adoption of sustainable energy technology as posited by Dincer as cited in He (2014) has been observed as a promising route to achieving sustainable development goals of clean and green energy; because the adoption will address several social and environmental problems such as clean energy deficit, air pollution, climate change, poverty among others.

Despite the abundance of sustainable energy sources in Nigeria, the over-dependence on fossil fuel energy for automobiles, plants and machines and usage for domestic purposes, over-reliance on National grid for electricity supply is a pointer that adoption of sustainable energy technology is very low among energy consumers 
in Nigeria. Also, gaining independence from fossil fuels and fighting climate change are the main factors that could increase the generation of energy from renewable fuels (Ahmad, Tahar, Chang \& Yao, 2017).

According to Oye (2016) sustainable energy market in Nigeria has the potential of generating an estimate of $\$ 7$ Million and 6000 jobs annually and these have been neglected over the decades. Thus, an understanding of the factors predicting the adoption of sustainable energy technology is essential for the energy marketers, government policy makers, sustainability entrepreneurs and energy consumers. Moreover, understanding which key predictors influence consumer adoption of sustainable energy technology that suit consumers' task, communication to actual and potential consumers and; proper formulation and implementation of marketing programme for energy market in Nigeria is very crucial taking Nigeria out of clean energy deficit and negative ecological footprint.

Extant literature on sustainable energy consumption has raised debate and arguments on the adoption of sustainable energy technology by energy consumers. Particularly, it is expedient and timely to identify which predicting factors influence the decision-making of energy consumers to adopt sustainable energy technology. Apart from this motivation, it is necessary to investigate why an individual adopts sustainable energy technology. These questions are the propelling force behind our endeavor.

Although, various studies have investigated consumer technology acceptance (See Hujits et al., 2012; Ahmad et al; 2017; Devine-Wright, 2007; Gonzalez, et al. 2016; Ntanos et al., 2018), most of these studies focused on a limited set of factors (either psychological or technological) that can influence consumer adoption, and were not based on a comprehensive conceptual and theoretical framework. Also, most studies on sustainable energy technology adoption were carried out in the developed economies of the world (See Divine-Wright, 2007; Huijts, et al. 2012; Kotilainen \& Saari, 2018; Toft, 2014; Leijten, et al, 2014) but for a typical sub-Saharan Africa country that is also a developing country like Nigeria, no such study has been conducted at least to the best knowledge of the researcher. Furthermore, research findings from these developed economies of the world cannot be applied to developing economies due to their peculiarities in terms of social, economic and political settings. Therefore, it is vital and necessary to carry out a country and context-specific empirical investigation in order to address this current gap in literature in the fields of sustainability marketing. Based on this, the general objective of this study is to empirically investigate the predictors of sustainable energy technology adoption in South-West Nigeria and develop a comprehensive policy framework and integrated conceptual model for sustainable energy technology adoption in a typical developing economy like Nigeria. Accordingly, this study reviewed related literature in the field of sustainable energy consumption, materials and methods adopted in this study was discussed alongside the result, conclusion and recommendations.

\section{Review of Related Literature}

\subsection{Sustainable Energy: The Nigeria Perspective}

A sustainable energy system may be regarded as a cost-efficient, reliable, and environment-friendly energy system that effectively utilises local resources and networks. It is not 'slow and inert' like a conventional energy system, but it is flexible in terms of new techno-economic and political solutions (Oyedepo, 2012). Access to clean, secure, sustainable, affordable and reliable energy has been a cornerstone of the world's increasing prosperity and economic growth. And this is a prerequisite for sustainable development in developing countries such as Nigeria. Energy sufficiency and security is a key to development and prosperity since it provides essential inputs for socioeconomic development at regional, national and sub-national levels; thereby providing vital services that improve the quality of life (Singh \& Sooch, 2004). Figure 1 shows the interrelationships between access to energy and sustainable development. The access to affordable energy is an essential component of achieving the Millennium Development Goals and UN Sustainable Development Goals for Nigeria (Amigun et al., 2011; Mohamad \& Anuge, 2016).

The demand for sustainable energy in Nigeria is increasing due to population and developmental growth. Unfortunately, the available infrastructures for providing and extending this required energy especially to rural areas have continued to diminish and have become grossly inadequate in recent times. Moreover, the persistent energy crisis in Nigeria has weakened industrialisation in the country. This has significantly undermined efforts to achieve sustained economic growth, increased competitiveness of indigenous industries in domestic, regional and global markets as well as employment generation (Iwayemi, 2008). The realisation of this fact necessitates the need for the nation to identify and promote the development and utilisation of alternative sources of energy such as biomass to augment the existing ones for the socio-economic development of the unreached rural areas of Nigeria. Many researchers have looked into the availability and potential of biomass energy resources in Nigeria with a view to establishing their viability and utilisation as sources of energy (gaseous, liquid or solid fuel) in the country. Oyebanji et al. (2017) investigated chemical composition of bio-oils produced by fast pyrolysis of two energy biomass. In the study, bio-oils from fast pyrolysis of West African cordia $(\mathrm{Cm})$ and Africana birch (Al) sawdust were analysed using a gas chromatography-mass spectrometry (GC-MS) analyser. Result of the study established that pyro-fuel not only can be used as fuel but can also be purified and serve as raw materials for chemical and processing industries. 
Exploration of the potential of biodegradable organic waste as a source of methane gas for electricity generation in Nigeria was carried out by Amasuomo and Ojukonsi (2015). In the study, a laboratory experiment was conducted using biodegradable organic solid waste collected from selected location in Nigeria. Results of the study revealed that anaerobic digestion could play a major role towards the attainment of sustainable solid waste management in Nigeria. The laboratory sample of 10 grams of solid waste produced about 0.796 litres of methane gas, and this implies that 1 tonne of organic waste in Nigeria will generate about 79,600 litres of methane gas with energy equivalent of about 1.592 MJ. Ozoegwu et al. (2017) assessed biomass and bioenergy potential of cassava waste in Nigeria. The aim of the study was to review the history, production, food value, economic value and bioenergy value of cassava. In the study, procedure for estimating cassava non-food biomass $(\mathrm{CnFB})$ from harvest data was established. The procedure entailed use of statistical sampling and regression analysis to establish scaling factors for transforming the data to CnFB. A real case study reflected very accurate and statistically significant error indices. The factors and literature data were used to make long-term projections of CnFB potential of Nigeria.

The potentials of microalgae biodiesel production in Nigeria was investigated by Ogbonna et al. (2015). The study showed that Nigeria has enabling environment for large-scale microalgae cultivation but lacks the policy framework that translates to effective production and utilisation of biodiesel. The authors concluded that, with the species of microalgae already isolated which contains more than $50 \%$ oil and assuming biomass productivity of $30 \mathrm{~g} / \mathrm{m} 2 . \mathrm{d}$ in a $10 \mathrm{~cm}$ deep open pond on a plot of land $(50 \mathrm{~m} \times 100 \mathrm{~m})$ will yield $75 \mathrm{~kg}$ of oil every day.

Garba and Zangina (2015) assessed the quantity of rice straw and husk produced as potential sources for minigrid rural electricity in Nigeria. The study showed that Nigeria has the potential to produce 434.6 million t of rice straw and 0.9 million $t$ of rice husk that could be used to generate $337.67 \mathrm{MW} /$ year of electric power at a conversion rate (rice straw and rice husk to power) of $1.7 \mathrm{~kg}$ of rice husks/straw per $\mathrm{kWh}$ of electricity, which represents about $7.64 \%$ of the current country's current power output.

Assessment of biogas energy use in Nigeria was carried out by Akinbami (2001). The study indicated that the identified feedstock substrate for an economically feasible biogas program in Nigeria includes water lettuce, water hyacinth, dung, cassava leaves, urban refuse, solid (including industrial) waste, agricultural residues, and sewage. The authors' views include the following: Nigeria produces about 227,500 tonnes of fresh animal wastes daily. Since $1 \mathrm{~kg}$ of fresh animal wastes produces about $0.03 \mathrm{~m} 3$ gas, then Nigeria could produce about 6.8 million $\mathrm{m} 3$ of biogas every day. In addition to all these, $20 \mathrm{~kg}$ of municipal solid wastes (MSW) per capital has been estimated to be generated in the country annually.

Audu and Aluyor (2012) examined the potentials of bioenergy and biofuels technology development in Nigeria. The study revealed that the co-production of biomass-based Fischer-Tropsch liquids and power could be an important step in a strategy to increase the contribution of bio-energy in the supply of energy in Nigeria. FischerTropsch liquids - (diesel and gasoline) could be introduced in the medium term, profiting from their compatibility with current fuel delivery infrastructure, and vehicle technologies.

Balogun (2015) carried out a study on the potentials for sustainable commercial biofuels production in Nigeria. The author recommended the implementation of national policy on biofuels and incentives, backed with required political - will, will ensure compliance on the delineation between crops, which should and should not be used for biofuel production, and as such, substantially puts to rest the anxiety over 'food for fuel' belief.

Simonyan and Fashina (2013) reviewed the biomass resources available in Nigeria and the potential of generating electricity from them. The authors also evaluated various biomass energy conversion technologies and the application of these technologies to development of Nigeria. The study showed that there exist great opportunities for exploitation of different types of biomass in Nigeria with an estimated 2.01 EJ (47.97 MTOE) biomass residues and wastes available to be exploited annually.

\subsection{Overview of Energy Sources and Current Energy Situation in Nigeria}

Nigeria is rich in both conventional and renewable energy resources that empower the country with a large capacity to develop an effective national energy policy. Presently, the country depends mostly on conventional source of energy with quite high opportunity cost making it cost-wise comparatively inaccessible for the poor population most especially the rural dwellers (Anowor et al., 2014). Worldwide, the country is ranked as the 10th largest crude oil producer with fossil fuels reserve estimates of about 37.140 billion barrels of crude oil (produces about 2.5 million barrels of crude oil per day), 182 trillion cubic feet ( $\mathrm{ft} 3$ ) of natural gas, and 209 million short tons of coal (Maijama'a et al., 2015; Onochie et al., 2015). With the available conventional energy reserves in Nigeria, it is obvious that Nigeria is a significant contributor to the world's fossil-based energy consumption Ozoegwu et al. (2017). However, production of energy for local use is still abysmally low (Giwa et al., 2017). The quality of electricity services in Nigeria remains poor and many Nigerians are still without access to regular electricity (Emodi \& Yusuf, 2015).

While energy either from conventional or renewable sources is needed to generate electricity for both economic and household sectors, one of the most important challenges Nigeria is facing for the past two decades is sustainable power supply (Maijama'a et al.,2015). The country has been facing persistent electricity problems 
ranging from power generation down to transmission and distribution. The gap between the electricity demand and supply has far exceeded that of any other country in the world. Nigeria is faced with chronic electricity crisis that has resulted in the crippling of most sectors of the economy.

There is therefore a call for sustainable development based on renewable energy sources. For maximum benefit and utilisation of vast available renewable resources, the over-dependence of the energy sector on fossil fuel that has slowed down the development of alternative fuels must be reversed (Giwa et al., 2017). There is the need for diversification to achieve a wider energy supply mix, which will ensure greater energy security for Nigeria. The way forward is the exploration of biomass which are abundant all over the country. As a renewable energy source, biomass products are sustainable, limitless and environment friendly. Bioenergy sources have significant potential to improve and make a difference on the low level access to clean energy and electricity in Nigeria (Aliyu et al., 2015). In addition to the problem of finite and fast depleting nature of fossil fuel, the adverse environmental impacts of fossil fuels, and deterioration of electricity transmission and distribution facilities have necessitated urgent massive investment in decentralised renewable energy technology (especially BET) (Chindo et al., 2014; Ozoegwu et al., 2017). This is possibly for Nigeria's energy security and environmental preservation.

\subsection{Diffusion and Adoption of Renewable Energy in Nigeria}

Stated below are some of the significant elements in national policy toward diffusion and adoption of renewable energy in Nigeria (ECN, 2003).

i. Harnessing hydropower potential available in country for electricity generation, also paying attention to the development of the mini and micro hydropower schemes.

ii. Exploitation of the hydropower resources in an environmentally sustainable manner and encouraging private sectors and indigenous participation in hydropower development.

iii. iii. Promoting the use of alternative energy sources to fuel wood by developing an appropriate technology to use wood chips rather than the direct use of wood.

iv. iv. Aggressive use and integration of solar energy into the nation's energy will be done, by developing the nation's capability in the utilization of solar energy as well as monitoring worldwide development of solar energy technology.

v. Developing wind energy resources and integrating them with other energy resources to form a balanced energy mix. It will as well involve taking necessary measures to ensure that wind energy is harnessed at a sustainable cost to both suppliers and consumers in the rural areas.

vi. Developing local capability in wind energy technology and applying it in areas where it is technically and economically feasible.

vii. Harnessing non-fuelwood biomass energy resources and integrating them with other energy resources.

Increasing the percentage of the contribution of hydro electricity to the total energy mix is yet to be achieved in the country; the survey carried out in harnessing hydropower is yet to be put into effect. Most of the rural areas in the country are still experiencing blackout due to the absence of electricity, while the current hydropower has in one way or the other contributed to ecosystem damage preventing fishermen from getting their daily bread. Furthermore, the maintenance of those available hydro electricity generating plants in the country is far below standard as a result of poor management of the whole system.

About $60 \%$ of Nigeria's population is highly dependent on fuelwood for cooking and other domestic uses. The use of fuelwood arises as a result of lack of appropriate cooking methods. This is not limited to the rural environment alone: even people in the urban area use it as well. It is discerned that the rate of fuelwood consumption far exceeds the replenishing rate, which has resulted in environmental setback. Therefore, the use of innovative ways of cooking is urgently needed both in the rural areas and the urban areas in order to curb the results of global warming.

\subsection{The Importance of Renewable Energy in Nigeria}

Renewable Energy World.com (2013) highlights that renewable energy is important because of the benefits it provides. The key benefits are as listed below:

i. Environmental Benefits

Renewable energy technologies are clean sources of energy that have a much lower environmental impact than conventional energy technologies.

ii. Energy for our children's next generations

Renewable energy will not run out. Other sources of energy are finite and will someday be depleted.

iii. Jobs and the Economy

Most renewable energy investments are spent on materials and workmanship to build and maintain the facilities, rather than on costly energy imports. Renewable energy investments are usually spent within the United States, frequently in the same state, and often in the same town. This means your energy dollars stay home to create jobs 
and fuel local economies, rather than going overseas. Meanwhile, renewable energy technologies developed and built in the United States are being sold overseas, providing a boost to the U.S. trade deficit.

iv. Energy Security

After the oil supply disruptions of the early 1970s, our nation has increased its dependence on foreign oil supplies instead of decreasing it. This increased dependence impacts more than just our national energy policy.

\subsection{Technological and Technical Inadequacies}

These encompass a whole range of issues, including insufficient resource data; substandard product quality; inadequate research and development activity; unsolved engineering problems, ignorance of advanced production techniques, limited human and manufacturing capacities. Engineers are not well trained in renewable energy technology and thus are not conversant with the best applications and limitations of different technologies. Lack of local skilled labour to operate and maintain renewable energy equipment is another major deterrent to the widespread adoption of BET, especially in rural Nigeria. Particularly in remote areas with restricted access, onhands maintenance is needed since frequent visits by repair and maintenance staff is difficult. Failure to provide regular maintenance of the equipment when it is required leads to their complete breakdown, thereby defeating the purpose of the initial investment.

\subsection{Insufficient-funding}

Inadequate financial and institutional infrastructure is a serious barrier to the rapid uptake and development of renewable energy technologies in Nigeria, particularly for the BETs such as improved wood burning stoves and biomass briquetting market development. Loan facilities to rural farmers are low. Government incentives are also inadequate. The cultivation of biofuel crops requires long-term loans and greater incentives. The poverty level in rural areas impedes farmers from getting loans, thus affecting their productivity.

\subsection{Uneven Distribution of Biomass Resource}

Even though Nigeria is endowed with abundant biomass energy resources in the form of fuelwood, crop residues, agricultural crop wastes and animal wastes, energy crops, etc., the reserves are unevenly distributed within geopolitical zone and often occur at long distances from the main energy demand centres. The uneven distribution of resources can increase transportation costs, which can amount to $25 \%$ or more of the cost of fuelwood for instance. Hence, developing biomass conversion facilities in proximity to the existing petroleum refinery infrastructure could reduce the cost of setting up new stand-alone bio-refineries. Nationally, the existing petroleum refineries seem to have adequate processing and hydro-treating facilities to convert bio-derived oils to transportation fuels.

\section{Low conventional energy prices due to government subsidies}

Low conventional energy prices hold back the development of alternative supplies even if they benefit most energy users in the shorter-term. This study does not advocate high-energy prices per se, but prices, which cover all costs. This would imply some increase in prices, which would help extend available resources, and encourage the bringing on of alternative sources and substitutes. Higher energy prices may eventually create the conditions whereby cheaper services can be delivered.

\section{Prospects of Sustainable Energy Technology Adoption in Nigeria}

There are enormous benefits stand to gain if sustainable energy technology is adopted in Nigeria. These benefits include:

\subsection{Potential environmental benefits}

Potential environmental benefits to be derived from the local production and use of biomass resources and biofuel production include offsetting GHG emissions associated with burning fossil fuels, waste utilisation, and erosion control. Clearly, biomass technology may benefit the environment while at the same time it may help solve some pressing environmental problems. It has been shown that using biomass to produce energy is carbon-neutral because it releases roughly as much carbon dioxide $(\mathrm{CO} 2)$ as it takes in. For instance, for every MWh of power generated using biomass, approximately 1.6 tonnes of $\mathrm{CO} 2$ are avoided. Biomass existing in form of solar energy kept in chemical form in plant and animals materials remains the alternative option not for power generation only but also for numerous purposes. It gives food, medicines, energy, building materials, papers, fabric, and chemicals to mention a few. Also, its contribution to the global warming is zero, a plus for the alternative form of energy. Again, biomass fuel has extremely minimal influence on the acid rain due to almost zero amount of sulphur in its content. 


\subsection{Socio-economic benefits}

The current global interest in biomass resource and biofuel production, especially in the area of transportation fuels, presents an opportunity for both domestic and foreign investment in Nigeria as well as increased export earnings. Also, because biomass resources can be converted to liquid and gaseous fuels, electricity and process heat, they can increase access to modern forms of energy for the population. Biomass resource cultivation, harvesting, and processing could have a direct impact on rural development. Biomass and biofuels production could improve rural livelihoods by providing new income opportunities to their families. Also, development of BET in Nigeria would boost agricultural development and technological advancement, and further bring opportunities, thereby improving the quality of life of the people.

\subsection{Benefits of accessibility to Clean Decentralized Energy System}

A variety of BETs that can convert renewable energy sources into more useful and convenient forms (gaseous fuels, liquid fuels, electricity, heat or shaft power) are commercially available. Their modular nature and the fact that they are more evenly distributed than conventional energy resources render BETs ideal candidates for providing decentralised energy services. Therefore, promoting BETs in Nigeria would contribute to sustainable energy development. To achieve this, appropriate institutional, legal, regulatory and fiscal framework must be put in place to address some of the barriers that are hindering their widespread dissemination in the country.

\section{Hypotheses Development}

\subsection{Performance expectancy and Adoption Intentions}

Performance expectancy (PE) can be defined as "the degree to which the user expects that using a system will help him or her to attain gains in job performance" (Venkatesh et al., 2003). More concrete this means that people are more likely to adopt new technologies when they believe this will help them to perform their job.

Venkatesh et al. (2003) integrated five concepts from various models into the construct of performance expectancy, namely perceived usefulness, extrinsic motivation, job-fit, relative advantage and outcome expectations. The concept of perceived usefulness was introduced by Davis (1986) in the Technology Acceptance Model and adapted by Taylor and Todd (1995) in their C-TAM-TPB. The definition of this concept is similar to the one of performance expectancy and refers to an individual's perception about the likelihood that the use of a system will enhance his or her performance on the job (Davis, 1986; Taylor and Todd, 1995). When the encouragement to perform an activity is achieving external outcomes, the motivation to do this is called extrinsic. Examples of extrinsic motivation are rewards and punishments such as salary, grades or promotions (Davis et al., 1992). Job-fit as a third concept can again be explained by the belief of an individual that accepting the technique or technology will lead to gains in job performance (Thompson et al., 1991). The extent to which an individual perceives a new technology as being more useful than the previous one, simply explains the concept of relative advantage (Rogers, 1995). Bandura (1986) introduced outcome expectations in his Social Cognitive Theory. This concept is divided into performance-related (or job-related) and personal-related outcome expectations (e.g. sense of accomplishment and self-esteem). The similarities between these concepts are acknowledged by several researchers (Davis, Bagozzi, \& Warshaw, 1989; Plouffe, Hulland, \& Vandenbosch, 2001).

The relationship between performance expectancy and the intention to use or the actual use of new technologies in healthcare settings has been the subject of many research questions. In studies executed around the world the techniques or technologies are diverse, ranging from electronic medical records to robotic-assisted surgery (Arman \& Hartati, 2015; BenMessaoud, Kharrazi, \& MacDorman, 2011). All hypothesized that performance expectancy predicts the acceptance of IT in healthcare organizations and most of them found evidence for this assumption (Phichitchaisopa \& Naenna, 2013; Van der Vaart, Atema, \& Evers, 2016). Although these results indicate a clear answer to the hypothesis, other researchers did not find a statistically significant effect of performance expectancy on behavioural intention or actual use (Schaper en Pervan, 2007; Vanneste, Vermeulen, \& Declercq, 2013). Devolder, Pynoo, Sijnave, Voet and Duyck (2012) found that the UTAUT predictors had different weights dependent on the subgroup studied and thus suggest that every type of people should be treated separately. We therefore hypothesized as follows:

$\mathbf{H}_{1}$ : Performance expectancy has a positive and significant effect on the intention to adopt sustainable energy technology.

\subsection{Effort expectancy and Intention to Adopt Sustainable Energy Technology}

The second concept, effort expectancy, can be defined as "the degree of ease associated with the use of the system" (Venkatesh et al., 2003). Similar to performance expectancy, Venkatesh et al. (2003) captured three constructs from other models into this concept, that is, perceived ease of use, complexity and ease of use. The first one, perceived ease of use, is a concept from the Technology Acceptance Model (Davis, 1986) which refers to the idea of someone that using the new technology will be effortless. The second concept integrated in effort expectancy, is complexity of the MPCU (Thompson et al., 1991).Complexity in this model, to be understood as the difficulty 
to use a system, as perceived by the users. Ease of use as a last concept, is a core construct of the IDT (Rogers, 1995) and its definition is apart from one difference equal to the one of complexity. The definition of complexity concerns a general system whereas ease of use is about an innovation (Venkatesh et al., 2003).

The hypothesis that effort expectancy positively affects the behavioural intention to use, as well as the actual use of a technique or a technology, has regularly been formulated in previous studies (Arman \& Hartati, 2015; Chang, Hwang, Hung, \& Li, 2007; Phichitchaisopa \& Naenna, 2013). Most researchers found support for this relationship (Chang et al. 2007; Phichitchaisopa \& Naenna, 2013), but others concluded that effort expectancy had no significant influence (Arman \& Hartati, 2015; Bennani \& Oumlil, 2013). Arman and Hartati (2015) argue that the characteristic of the sample could have been the possible explanation. Almost $70 \%$ of the participants had a maximum age of 50 years and $67 \%$ were specialists with a lot of experience, and as previously mentioned age and experience both moderate the effect of effort expectancy (Arman \& Hartati, 2015; Venkatesh et al., 2003). Based on the forgoing, we proposed as follows:

$\mathbf{H}_{2}$ : Effort expectancy has a positive and significant effect on the intention to adopt sustainable energy technology.

\subsection{Social influence and Intention to Adopt Sustainable Energy Technology}

According to the UTAUT social influence of "the degree to which an individual perceives that important others believe he or she should use the new system" (Venkatesh et al., 2003) is the third and last direct determinant of the behavioural intention to use a technique or technology (Venkatesh et al., 2003). The three concepts included in social influence are: subjective norm, social factors and image. Each of these concepts refer to the notion that the social environment has a substantial influence on the way people act (Venkatesh et al., 2003). Subjective norm was introduced in the TRA by Ajzen and Fishbein (1977), then used by Ajzen (1985) in his TPB and by Taylor and Todd (1995) in their C-TAM-TPB. Venkatesh and Davis (2000) extended the Technology Acceptance Model by including subjective norm as an extra concept for the prediction of behavioural intention. Their new model was called TAM2. The concept can be explained by one's perception about how important others think he or she should act. Social factors as a second concept integrated in social influence refers to the internalisation of the culture and social agreements the individual shares with others (Venkatesh et al., 2003). Social factor is a core construct of the Model of PC Utilization by Thompson et al. (1991). The third concept, image, is introduced in the IDT by Rogers (1995) and can be understood as the perception that the use of a new technique or technology will upgrade a person's image or social status.

Based on the UTAUT, researchers often want to investigate the hypothesis that social influence has a positive effect on the behavioural intention to use, and the actual use of a technique or technology (Arman \& Hartati, 2015; Chang et al., 2007; Phichitchaisopa \& Naenna, 2013). Although some researchers found social influence was the most salient predictor (Alaiad \& Zhou, 2014), others found that the effect was only marginally significant (Chang et al., 2007). Indeed, some studies even had to reject the hypothesis, because the effect of social influence did not achieve significance (Bennani \& Oumlil, 2013; Phichitchaisopa \& Naenna, 2013).

$\mathbf{H}_{3}$ : Social Influence has a positive and significant effect on the intention to adopt sustainable energy technology.

\subsection{Facilitating Condition and Intention to Adopt Sustainable Energy Technology}

Facilitating conditions refers to consumers' perception that technical infrastructure exists to support the use of technology (Vankatesh, 2012; Yeoh \& Chang 2011, Brown, 2005). In UTAUT, facilitating conditions were theorized to determine the technology use. Based on the forgoing, we hypothesized as follows:

$\mathbf{H}_{4}$ : Facilitating condition has a positive and significant effect on the intention to adopt sustainable energy technology.

\subsection{Intrinsic Motivation and Intention to Adopt Sustainable Energy Technology}

Intrinsic Motivation is defined as "the fun or pleasure derived from using a technology (Vankatesh \& Thong, Xu Brown 2012). In previous technology acceptance studies, it has been shown to be an importance factor in determining the acceptance of technology (Brown \& Vankatesh, 2005). Sequel to this assertion, we hypothesized as follows:

H5: Intrinsic motivation has a positive and significant effect on the intention to adopt sustainable energy technology.

\subsection{Nexus Between Price Value and Intention to Adopt Sustainable Energy Technology}

In marketing research, the monetary cost is usually conceptualized together with the quality of products or services (Zeithaml, 1988), we follow these ideas and define price value as consumers' cognitive tradeoff between the perceived benefits of the applications and the monetary cost for using them (Dodds, 1991). Unlike organizational technologies, individuals pay for the cost of adopting and using a technology or product on their own (Zhou, 2013). On the basis of the foregoing, we hypothesized as follows:

$\mathbf{H}_{6}$ : Price value has a positive and significant effect on the intention to adopt sustainable energy technology. 
4.7 Relationship Between Intention to Adopt and Actual Adoption of Sustainable Energy Technology

Ajzen and Driver (as cited in Tsai, 2009) stated that behavioral intention can influence actual behavior effectively. Willingness is a major predictive factor and behavioral intention is an important factor influencing actual behavior (Blue, Gopi \& Ramayah as cited in Tsai, 2009). It is from this claim that we hypothesized as follows:

H$_{7}$ : There exists a significant relationship between patronage intention and actual patronage of Sustainable energy technology.

\section{Theoretical Perspective}

This study centers on the predicting factors governing sustainable energy technology adoption and its usage among energy consumers. The conceptual framework of this study is shown in the figure below. The main theme of this study is to determine consumers' adoption of sustainable energy technology based on the unified theory of acceptance and use of technology (UTAUT). The reason for choosing UTAUT is mainly because of the broad objective of this study and also UTAUT integrated eight models from previous studies. This will help arrive at a robust and comprehensive sustainable energy technology adoption (SETA) policy framework for Nigerian energy market. UTAUT model integrates the issue that are mentioned in the extant sustainability marketing literature into four main core determinants: Performance Expectancy (PE), Effort Expectancy (EE), Social Influence (SI), Facilitating Conditions (FC) and four control variables, which are gender, age, experience, and voluntariness of use. The purpose of UTAUT model is to offer marketers the tool to weigh the introduction of new technology, predict and explain the user's behaviour of accepting, adopting or using technology (Venkatesh et al, 2003).

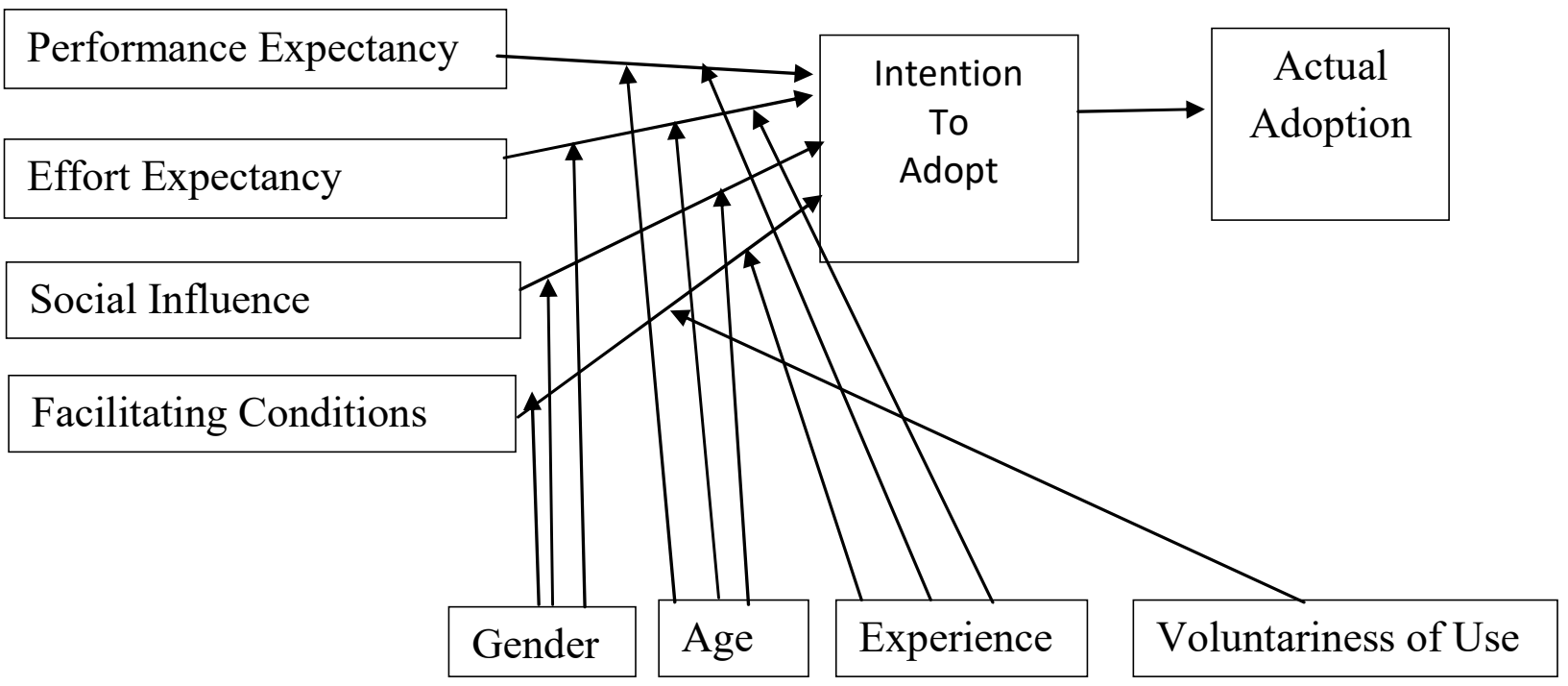

Source: Venkatesh, et al. (2003)

\section{Empirical Review}

Ahmad, Tahar, Cheng and Yao (2017) carried out a study with the purpose to examine the extent of solar photovoltaic technology acceptance by Malaysian energy consumers. In order to achieve this objective, their study used Technology Acceptance Model (TAM) has the theoretical framework. A survey research design was adopted and 663 out of 780 copies of questionnaire were returned and validated for the study. Collected data were analysed using descriptive analysis while the formulated hypotheses were tested using inferential statistics. It was found that perceived ease of use, attitude to use and perceived usefulness have significant influence on behavioural intentions to use solar photovoltaic technology.

Sardianou and Genoudi (2013) conducted a study aimed at determining the consumers' willingness to adapt renewable energies in the residential sector of Anthens Greece. A cross sectional data between December 2009 to January 2010 were collected from 200 respondents using stratified random sampling. The data were analysed using Probit regression analysis. The findings revealed that marital status and gender are statistically insignificant factors in the willingness to adopt renewable energy. Financial incentives were statistically significant factor so as tax deductions, energy subsidy and the price of energy.

Similarly, a study was done in Nikaia, Greece by Ntanos, Kyriakopoulos, Chalikias, Arabatzis and Skordoulis (2018) which focused on the discovery of factors that shape public opinion about renewable energy sources and empirically investigate the willingness to pay for expansion of renewable energy sources in the electricity mix. Data were collected from 398 respondents statistically drawn from 89,380 residents in the study area. Data collected were tested using principal component analysis, one-way ANOVA and hypotheses were tested using 
binary logit regression with aid of Stata/MP 13.0 and SPSS 17. It was revealed statistically that there exist a relationship between renewable energy sources perceived advantages and willingness to pay was positively related to education, energy subsidies and state support.

More so, Kotilainen and Saari (2018) conducted a study to explore consumers' attitudes towards using renewable energy technology and how policies could influence consumers' interests by turning them to prosumers. The survey design was conducted in 5 European countries and the partial least square Structural Equation Modeling (PLS-SEM) method was employed to analyse the data collected. It was shown that both economic and non-economic policies affect consumer attitudes towards renewable energy technologies adoption.

Furthermore, a study conducted in Iran by Komendantova, Yazdanpanah and Shafiei (2018) was aimed at studying the deployment of renewable energy sources among young people using social cognitive theory as a reference framework. A cross-sectional survey was conducted among the students of University of Esfanhan, Iran. A sample of 260 students was randomly selected using random sampling. Hypothesized relationships were tested using structural equation modeling (SEM) with the aid of AMOS 20. It was revealed that there exists a positive influence of self-rewarding to encourage young people to participate in energy transition and social outcome expectation is a major driver.

In similar vein, Feng (2012) carried out a study with the purpose of analyzing the major factors influencing users' intentions to adopt renewable energy technologies in Taiwan. In order to achieve this, 273 respondents formed the survey and the research was anchored on the theory of reasoned action, technology acceptance model and Roger's diffusion of innovation model. Structural equation modeling was adopted to test the hypothesized relationship between the variables of study. It was found out that innovation acceptance and subjective norm positively influence renewable energy technology intentions to adopt while external variable of the users and attitude towards the renewable energy technology usage partly influenced its adoption.

Moreover, Leijten, Bolderdijk, Keizer, Gorsira, Weff and Steg (2014) did an empirical study among 139 Dutch citizens (aged 18-85). The aim of the study is to find out the factors influencing consumers' acceptance of future energy systems. Experimental design and questionnaire were adopted as the research design and instrument respectively. Conjoint analyses were done to test the data collected. It was revealed that respondents preferred making adjustments rather than reliance on technology to do so for them. Also, consumers failed to exhibit a clear preference for any of the displayed production level.

Also, Zahari and Esa (2016) carried out a study on the drivers of renewable energy adoption behavior among the residents of Klang valley in Malaysia. A total of 501 respondents were used for the study. A self-administered questionnaire was employed via convenience sampling. Data collected were analysed using SEM partial least square while a bootstrap resampling procedure was conducted to estimate the coefficients. It was revealed that the intentions to adopt renewable energy are influenced by perceived utility of new technology, perceived benefit of new technology and perceived utility of a new service.

Ing, Keong, Hong, Yan, Wei, and Ching (2019) in their study conducted among Malaysian consumers which was aimed at determining the factors affecting consumers' perception towards renewable energy among adults in Kuala Lumpur. The study data were collected using survey questions on respondents between age 21-50 years. Correlation and multiple regression were used to test the data. It was found that global and local economic factors contribute most to consumers' perception towards renewable energy while perceived product benefit has no significant relationship.

\section{Materials and Methods}

The research philosophy/paradigm that guided this study was positivism. Positivist research approach, according to Carr (2016) shows the relationship between or among variables of a given study. This research philosophy was adopted because the general objective of this study is to test the hypothesized relationship between the independent variables (predictors) and dependent variables (adoption of sustainable energy technology). The research design for this study was quantitative research design. This type of research design was adopted because it places emphasis on using formalized questions and pre-determined response options in questionnaire administered to large numbers of respondents (Kothari, 2004). The population of study (unit of analysis) comprised energy consumers that possess at least a minimum of higher education qualification in South-West geo-political zone of Nigeria. Energy consumers are those who have the willingness and the purchasing power to purchase any type of energy for electricity, automobile or for any other similar reasons. The choice of energy consumers with at least higher education qualification helped in the selection of consumers that have the potential to understand the topic under study and were able to contribute meaningfully. The sample size was determined by using a formula that estimates the representativeness of the sample on certain parameters (were based on pilot study) at an acceptance level of probability i.e. Topman's formula. This kind of formula for sample size determination is suitable for this study since the study population is infinite - there is no sampling frame for energy consumers in Nigeria.

Quota sampling technique was adopted. Quota sampling involves segmenting the sample size into quota based on certain criteria like demographic or psychographic variables though disproportionately. The six south- 
western states were clustered as follows: 1. Lagos and Ogun, 2. Oyo and Osun, 3. Ondo and Ekiti. The justification for the clustering was on the basis of cultural similarity. One state out of the three clusters was selected on the basis of population, industrialization, and year of creation. In this case, Lagos, Oyo and Ondo states were chosen to participate in the study. Furtherance to this, each selected state was segmented into three senatorial zones and the most urban local government in each zone was selected for the study. The research instrument adopted was structured questionnaire. The kind of questions the questionnaire adopted was a scaled - question i.e. Likertsummated scale. The research instrument was validated using construct validity and tests while the internal consistence of the research instrument was tested using composite reliability test. Structural Equation Modeling (SEM) was used to test the hypothesized relationship among the variables and analyze the proposed research model.

\section{Results}

8.1 Reliability and Validity of the Research Constructs

Table 1: Construct Validity of Research Items

\begin{tabular}{|c|c|c|c|c|c|}
\hline Measurement Items & Loadings & S.E. & Reliability & $\mathbf{C R}$ & AVE \\
\hline \multicolumn{6}{|c|}{ Performance Expectancy } \\
\hline PFE1 & 0.7500 & 0.4375 & 0.5625 & & \\
\hline PFE2 & 0.9040 & 0.1828 & 0.8172 & & \\
\hline PFE3 & 0.7660 & 0.4132 & 0.5868 & 0.8500 & 0.6555 \\
\hline \multicolumn{6}{|l|}{ Effort Expectancy } \\
\hline EFEXP1 & 0.7920 & 0.3727 & 0.627264 & & \\
\hline EFEXP2 & 0.7920 & 0.3727 & 0.627264 & 0.77094 & 0.6273 \\
\hline \multicolumn{6}{|l|}{ Social Influence } \\
\hline SOCINF1 & 0.83 & 0.3111 & 0.6889 & & \\
\hline SOCINF2 & 0.818 & 0.3309 & 0.6691 & & \\
\hline SOCINF3 & 0.599 & 0.6412 & 0.3588 & 0.79736 & 0.5723 \\
\hline \multicolumn{6}{|l|}{ Facilitating Condition } \\
\hline FACON1 & 0.6020 & 0.637596 & 0.362404 & & \\
\hline FACON2 & 0.7420 & 0.449436 & 0.550564 & & \\
\hline FACON3 & 0.7580 & 0.425436 & 0.574564 & & \\
\hline FACON4 & 0.6230 & 0.611871 & 0.388129 & 0.77756 & 0.4689 \\
\hline \multicolumn{6}{|l|}{ Price Value } \\
\hline PRVC1 & 0.823 & 0.322671 & 0.677329 & & \\
\hline PRVC2 & 0.823 & 0.322671 & 0.677329 & 0.80763 & 0.6773 \\
\hline \multicolumn{6}{|l|}{ Intrinsic Motivation } \\
\hline INSMOT1 & 0.857 & 0.265551 & 0.734449 & & \\
\hline INSMOT2 & 0.829 & 0.312759 & 0.687241 & & \\
\hline INSMOT3 & 0.503 & 0.746991 & 0.253009 & 0.78334 & 0.5582 \\
\hline \multicolumn{6}{|l|}{ Adoption Intention } \\
\hline BEHVINT1 & 0.753 & 0.432991 & 0.567009 & & \\
\hline BEHVINT2 & 0.864 & 0.253504 & 0.746496 & & \\
\hline BEHVINT2 & 0.8 & 0.36 & 0.64 & 0.84808 & 0.6512 \\
\hline \multicolumn{6}{|l|}{ Actual Adoption } \\
\hline ACTBEHV1 & 0.784 & 0.385344 & 0.614656 & & \\
\hline ACTBEHV2 & 0.784 & 0.385344 & 0.614656 & 0.76135 & 0.6147 \\
\hline
\end{tabular}

Table 1 reflects the reliability and validity of items included in the research instrument. The item loading, composite reliability (CR), and average variance explained (AVE) of the constructs are as indicated in the table above. Most of the AVE values are greater than 0.50, suggesting convergent validity at the construct level. All CR values are greater than 0.70 , suggesting that the reliability of the research items are acceptable. Also the factor loadings of above 0.7 indicates acceptable values (Peng \& Lai, 2012). 
Figure 2: Regression Path Model of between the Variables

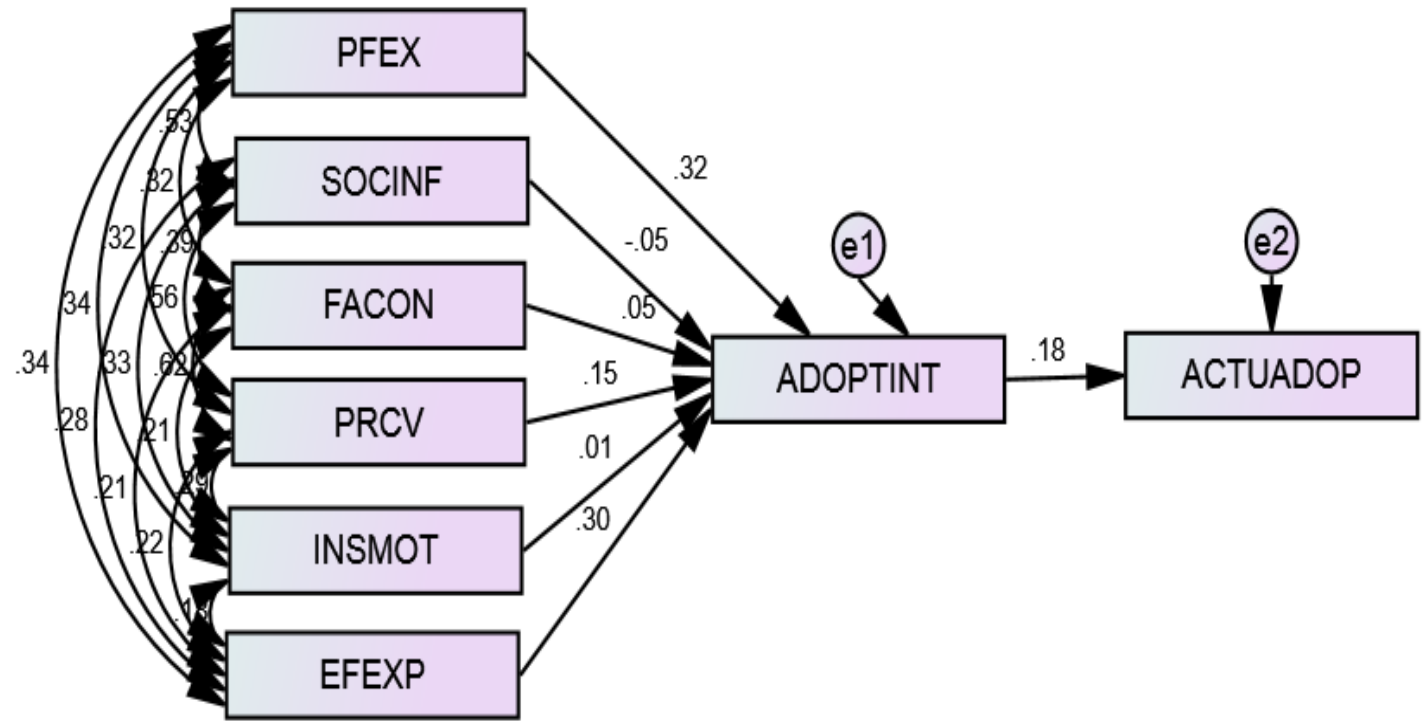

The above Figure 2 shows the path analysis model of multivariate relationships between the research variables. The results provided in the analysis results indicate a minute but positive relationships between intrinsic motivation and facilitating conditions and adoption intention $(\mathrm{r}=0.01)$ and $(\mathrm{r}=0.05)$ respectively. More significant positive influences are observed from performance expectancy $(\mathrm{r}=0.32)$, price value $(0.15)$ and effort expectancy $(\mathrm{r}=0.30)$ on adoption intention. However, social influence demonstrates a negative, yet minute effect on adoption intention $(r=-0.05)$. As depicted in Figure 1 above, the relationship between adoption intention and actual adoption is quiet significant and positive $(\mathrm{r}=0.18)$.

Table 2: Regression Weights between the Research Variables

\begin{tabular}{|lll|r|r|r|r|r|}
\hline & & & Estimate & S.E. & C.R. & P & Label \\
\hline ADOPTINT & $<---$ & PFEX & .425 & .079 & 5.353 & $* * *$ & Relationship Exist \\
\hline ADOPTINT & $<---$ & SOCINF & -.056 & .077 & -.728 & .467 & No Relationship \\
\hline ADOPTINT & $<---$ & FACON & .085 & .105 & .805 & .421 & No Relationship \\
\hline ADOPTINT & $<---$ & PRCV & .222 & .099 & 2.237 & $* * *$ & Relationship Exist \\
\hline ADOPTINT & $<---$ & INSMOT & .012 & .060 & .195 & .845 & No Relationship \\
\hline ADOPTINT & $<---$ & EFEXP & .339 & .059 & 5.725 & $* * *$ & Relationship Exist \\
\hline ACTUADOP & $<---$ & ADOPTINT & .156 & .050 & 3.113 & $* * *$ & Relationship Exist \\
\hline
\end{tabular}

Table 2 above also shows the structural regression weights of the multivariate analysis. The model fit of the analysis is assured by the following indicators Chi-square/Degree of Freedom $(\mathrm{Cmin} / \mathrm{df})=12.750$, Goodness of Fit Index $(\mathrm{GFI})=0.945$, Normed Fit Index $(\mathrm{NFI})=0.883$, Comparative Fit Index $(\mathrm{CFI})=0.887$, Root Mean Square Error of Approximation (RMSEA) $=0.201$. The values are significant based on the arguments presented in established studies (Byrne, 1994; Hipp \& Bollen, 2003; Schumacker \& Lomax, 2010).

\section{Discussion}

The general objective of this study is to understand those predicting factors that influence the adoption of sustainable energy technology in a typical developing country context. Primarily, the study unveiled basic predictors of sustainable energy technology adoption behaviour. The findings of this study enriched the mainstream literature of the under-researched and under-reported activities of the highly informal food marketing sector of Nigeria although with huge potential return on investment.

Majorly, the first finding of this study is that the unified theory of acceptance and use of technology (UTAUT) is a comprehensive and robust theoretical framework for explaining, describing, and predicting sustainable energy technology adoption behaviour for an evolving concept that characterised a nascent market segment.

Moreover, this study lends voices to previous studies that advocate the use of UTAUT framework to predict sustainable energy technology adoption behaviour. The works of Feng (2012), Zahari and Esa (2016); Ing, Keong, Hong, Brandon, Wei and Ching (2017) supported the application of UTAUT as the most robust and comprehensive model to predict sustainable energy technology adoption behaviour.

Specifically, this study revealed various factors that shape sustainable energy technology adoption behaviour. It was shown that performance expectancy, price value and effort expectancy have significant relationship with 
intentions to adopt sustainable energy technology. This is in consistence with the work of Leijeten, et al.,(2014), Feng (2012), Zahari and Esa (2016); Ing, et al., (2017) that consumers of sustainable energy technology are very price-sensitive, they considered the performance of the Sustainable Energy Technology (SET) compared to the existing energy source they use and that the effort they put in acquiring SET is very crucial to their choice and adoption behaviour.

However, the study found out that social influence, intrinsic motivation and facilitating conditioning do not have positive and significant effect on the intentions to adopt SET. This implies that consumers of SET in Nigeria do not consider peer influence, external facilities like government support and inner motivation in the course of adopting SET. This finding is a deviation from the studies done by Ahmad, et al., (2017), and Komendantova, Yazdanpanah and Shafiei (2018). The reason for this deviation is unclear. It may be argued that variations in technology exposure level, difference in income level and variations in geographical locations as examined by the researchers could be responsible. For example, Ahmad, Tahar and Yao (2017) study was conducted in Malaysia; Sardianou and Genoudi (2013) conducted their study in Greece; Leijten et al. (2014) carried out their study in Nethrerlands. These geographical locations are considered to be well advanced in technological innovation than Nigeria.

\section{Conclusions and Recommendations}

This study has provided empirical support that UTAUT provides a robust and comprehensive theoretical framework to predict, explain and describe sustainable energy technology adoption behaviour in atypical developing country context like Nigeria. This is true especially when it is necessary and expedient to explain and describe in basic terms the drivers of SET adoption from the psychological and technological perspectives. Furthermore, the study concludes the emergence and existence of SET market segment within the energy market sector in Nigeria. This niche is growing as the sustainability orientations and awareness spread, increased energy consumption level and intense urbanisation become the order of the day (Ukenna \& Ayodele, 2019).

On the strength of the findings, we recommend as follow; the study revealed that performance expectancy, price value, and effort expectancy have significant and positive influence on adoption intentions for SET. The marketers of SET products should use price as their unique selling proposition to attract customers. Also, the quality of the SET products should conform with the expected performance of the product. Also, the SET marketers should endeavour that expected efforts of the prospective SET products consumers are met adequately since social influence, facilitating conditions and intrinsic motivation did not have significant effect on adoption intentions for SET. Skimming strategy will make marketing sense for the current SET marketers, once SET consumers perceive the marketer as reliable. Furthermore, innovative personal selling that is based on trust can be adopted by energy marketers in order to increase SET adoption rate.

\section{References}

Ahmad, S., Tahar, R.M., Chang, J.K. \& Yao, L. (2017). Public acceptance of residential solar photovoltaic technology in Malaysia. PSU Research Review, 1(3), pp. 242-254. DOI: 10.11.08/PRR-11-2016-009.

Ajzen, I. \& Fishbein, M. (1980), Understanding attitudes and predicting social behavior, 1st edition, Prentice-Hall, Eaglewood Cliffs, New Jersey.

Audu, T.O.K. \& Aluyor, E.O. (2012). Potential of bioenergy and biofuels technology development in Nigeria. Petroleum Technological Development Journal,1, 1-7.

Balogun, B.O. (2015). Potentials for sustainable commercial biofuels production in Nigeria. STECH, 4 (2), 2540.

Byrne, B.M. (1994). Testing for the factorial validity, replication, and invariance of a measurement instrument: A paradigmatic application based on the Maslach Burnout Inventory. Multivariate Behavioral Research, 29, $289-311$.

Carr, W. (2006). Philosophy, methodology and action research. Journal of Philosophy of Education. Vol. 40(4), pp. 421-435.

Davis, F.D. (1986). A technology acceptance model for empirically testing new end user information systems: Theory and result. Ph.D. dissertation, Sloan School of Management, Massachusetts Institute of Technology.

Devine-Wright, P. (2007). Reconsidering public attitudes and public acceptance of renewable energy technologies: a critical review. working paper 1.4, Manchester Architecture Research Centre, University of Manchester.

EIA Bioenergy (2012). Bioenergy - a Sustainable and Reliable Energy Source: a Review of Status and Prospects, 1-108, Energy Research Centre of the Netherlands (ECN), E4tech, Chalmers University of Technology, and the Copernicus Institute of the University of Utrecht, UK.

Energy Commission of Nigeria (2003). National Energy policy, Federal Government of Nigeria.

Feng, H. (2012). Key factors influencing users' intentions of adopting renewable energy technologies. Academic research international, 2 (2), 156-168.

Gonzalez, A.., Sandoval, H., A. Costa, P. \& Hengo, F. (2016). On the acceptance and sustainability of renewable 
energy projects - A system thinking perspective. Sustainability, 8(1171), 1-21, DOI. 10.3390/SU8111171.

He, P. (2014), The determinants of renewable energy technology adoption: Empirical evidence from China. A Masters Thesis from ETH Zurich, Switzerland.

Hipp, J. R. \& Bollen K. A. (2003). Model Fit in Structural Equation Models with Censored, Ordinal, and Dichotomous variables: Testing Vanishing Tetrads. Sociological Methodology, 33, 267-305.

Huitits, N.M.A., Molin, E.J.E. \& Steg, L. (2012). Psychological factors influencing sustainable energy technology acceptance: a review-based comprehensive framework. Renewable and sustainable energy reviews, Vol. $16(12)$, pp. 525-531.

Iwayemi, A. (2008). Nigeria's dual energy problems: policy issues and challenges. International Association for Energy Economics, 53, 17-21.

Kothari, C.R. (2004). Research Methodology: Methods and Techniques. 2nd revised edition, New Delhi, New Age International Limited.

Kotilainen, K. \& Saari, U.A. (2018). Policy influence on consumer evolution into prosumers - empirical findings from an exploratory survey in Europe. Sustainability, 10(186), pp. 1-22, DOI:10.3390/SU0010186.

Leijten, F.R.M. Bolderdijk, J.W., Keizer, K., Gorsira, M., Werff, E.V. and Steg, L. (2014). Factors that influence consumers' acceptance of future of future energy systems: the effects of adjustment type, production level, and price. Energy efficiency, 7, 973-985, DOI: 10.1007/S12053-014-9271-9.

Ntanos, S., Kyriakopoulos, G., Chalikias, M., Arabatzis, G. \& Skordonlis, M. (2018). Public perceptions and willingness to pay for renewable energy: a case study from Greece. Sustainability, 10(687), 1-16, DOI: $10.3390 /$ SU10030687.

Oye, F. (2016). Nigeri's \#1 Multi-Millionaires’ Business Coach swears Under Oath. 1-Watt Solar Club. Retrieved from http://www.1wattsolar.org on 26/01/2016.

Peng, D. X. \& Lai, F. (2012). Using partial least squares in operations management research: A practical guideline and summary of past research. Journal of Operations Management, 30, 467-480.

Rio, P. \& Burgillo, M. (2008). Assessing the impact of renewable energy deployment on local sustainability: towards a theoretical framework. Renewable and energy reviews, Vol. 12 (2008), pp. 1325-1344.

Rogers, E. (1995). Diffusion of Innovations. New York, NY: Free Press.

Schumacker, R. E. \& Lomax, R. G. (2010). A beginner's guide to structural equation modelling. (3rd ed.). New York: Routledge.

Simonyan, K.J. \& Fasina, O. (2013). Biomass resources and bioenergy potentials in Nigeria. African Journal of Agricultural Research. 8 (40), 4975-4989.

Singh, K.J. \& Sooch, S.S. (2004). Comparative study of economics of different models of family size biogas plants for state of Punjab, India. Energy Conversion \& Management, 45, 1329-1341.

Toft, M.B. (2014). Consumer adoption of sustainable energy technology - the case of smart grid technology. PhD thesis, Department of Business Administration Arhus University.

Ukenna, S.I. \& Ayodele, A.A. (2019). Applying the extended theory of planned behavior to predict sustainable street food patronage in a developing economy. Journal of Food Product Marketing, DOI: 10.1080/1045446.2019.1572561

Venkatesh, V., Morris, M.G., Davis, G.B. \& Davis, F.D. (2003), User acceptance of information technology: toward a unified view, MIS Quarterly, 27, 425-478.

Tsai, C. (2009). Applying the Theory of Planned Behavior to explore the independent travelers' behavior. African Journal of Business Management, 4(2), 221-234.

\section{Acknowledgements}

The authors which to acknowledge Centre for Research, Innovation and Development (CRID) of The Federal Polytechnic, Ado Ekiti, Nigeria and Tertiary Education Trust Fund (TETFUND) for funding this research work. 